\title{
Effects of Classroom Physical Environment on the Academic Achievement Scores of Secondary School Students in Kohat Division, Pakistan
}

\author{
Qaiser Suleman \\ Ph.D (Education) Scholar, Institute of Education \& Research, Kohat University of Science \\ \& Technology, Khyber Pakhtunkhwa, (Pakistan) \\ Email: Look_for_reality@yahoo.com \\ Dr. Ishtiaq Hussain \\ Assistant Professor, Institute of Education \& Research, Kohat University of Science \\ \& Technology Kohat, Khyber Pakhtunkhwa, (Pakistan) \\ Email: dr.ishtiaqkust@gmail.com
}

Doi:10.5296/ijld.v4i1.5174

URL: http://dx.doi.org/10.5296/ijld.v4i1.5174

\begin{abstract}
The purpose of the paper was to examine the effects of classroom physical environment on the academic achievement scores of secondary school students. All the students studying at secondary school level in Kohat Division, Pakistan constituted the population of the study. The study was delimited to the students of class 09 of Govt. High School Khurram (Karak). Forty students from class 09 of the same school were selected as sample through simple random sampling technique. The study was experimental in nature and therefore "Pre-test-Post-test Equivalent Groups Design" was used. Statistical data was collected through pre-test and post-test technique. Statistical tools i.e., mean, standard deviation and differences of means were calculated for each group. Significance of the difference between the mean scores of the experimental and control groups was tested at 0.05 level of confidence by applying t-test. After analysis, it was concluded that classroom favorable environment has a significant positive effect on the academic achievement scores of secondary school students. The students of experimental group showed better performance as compared to the students of control group. Based on findings, it was recommended that classroom physical environment should be well-organized, equiped and facilitated.
\end{abstract}

Keywords: Effects, Classroom Physical Environment, Academic Achievement Scores, Secondary School Students

\section{Introduction}

In determining the effectiveness of a national system of education, secondary education is universally acknowledged as a fundamental stage. Developed countries such as the United States and many of the European countries are focusing their concentration on research to explore better solutions to the escalating and emerging problems faced by the youth at secondary school level. Most of the people, who compose the skilled manpower of a nation, are trained before the end of their high school years. The quality of higher education depends upon the quality achieved at this level. The formation of character and foundations of future leadership are laid at this level, which comes at a time when the youth is in his formative adolescent stage (AIOU, 1998). It means that secondary education is the foundation stone for further studies and also for the development of a nation. Therefore, it is imperative to pay 
proper attention towards secondary education and revolutionary steps should be taken to make it more effective, successful and productive.

Classroom management is a critical part of effective and successful instruction. Effective classroom management, which initiates with well-organized and efficient lesson planning preparation, helps a teacher to teach and students to learn. Students perform well in an optimistic classroom atmosphere and an environment in which they feel secure, safe, cared for and involved. From a student point of view, effective and successful classroom management provides students with opportunities to socialize while learning interesting content. From a teacher point of view, effective classroom management involves preventive discipline and interesting instruction (Lang and Hebert, 1995). To ensure a favorable classroom environment, it should be well equipped and facilitated. The classroom physical arrangement provides students with effective instruction and promotes smooth teaching learning process. Physical facilities should be provided as they are helpful in improving the overall performance of the school.

Physical environment refers to physical characteristics of the room. Physical classroom environment is a combination of different things i.e., lighting, temperature, ventilation system, size of the room, floor, walls, desks, chairs, rugs, whiteboards, computers etc. Teacher and students are considered the main elements of the classroom environment. Favorable physical environment has a significant positive effect on the efficiency of any organization and acts as catalyzing agent to provide a straight way for achieving predetermined objectives of an organization. But unfortunately, physical environment in our classroom is not conducive for smooth teaching learning process resulting fatigue and frustration among the students. According to Halstead (1974), the physical environment is designed in such a way that obstructs the learning process although researches have established a close correlation between the amount of work individual do and its physical environment. It stands to reason that a student sitting in an insufferably hot, airless room listening to a lecture on cryogenics would not learn as much as he would in a cool, comfortable space. Unfortunately, college buildings are designed to attract people from outside but they failed to provide a safe and comfortable internal atmosphere for students.

The current paper was specially designed to examine the effects of classroom physical environment on the academic achievement scores of secondary school students. The findings of the study will bring a constructive revolution in classroom setting to ensure effective teaching learning process. Furthermore the findings of the study will be beneficial for teachers, policy makers, ministry of education because it will explore the effectiveness of classroom physical environment on the students' achievement at secondary school level.

\section{Review of Related Literature}

Research studies on the classroom environment have revealed that physical arrangement plays a vital role in teaching learning process. It can affect the performance of both teachers and students (Savage, 1999; Stewart and Evans, 1997). The learning setting is comprised of different things i.e., learners, teachers and the physical environment (Lippman, 2010). Physical environment is simply defined as the physical characteristics of the room. It refers to the different things i.e., size of the room, lighting, degree of temperature, condition of classroom floor whether it is carpeted or just concrete etc (www.enotes.com). Physical classroom environment refers to the physical room in which teacher and learners are the main element including its spatial elements i.e., floor, windows, walls as well as other classroom 
equipments i.e., desks, chairs, rugs, chalkboards, tack boards, easels, counters and computer equipment but not limited to these things (Fisher, 2008). Physical environment can affect students' comfort and also their ability to learn to some extent. Students who are comfortable are likely to get much information as compared to those who are uncomfortable. Besides, the physical atmosphere can also affect the morale of the learners. Unfavorable classroom environment can discourage the learners and they become less willing to learn (www.enotes.com).

Physical environment plays a central role in any activity and makes it more conducive, successful and achievable. According to Oni (1992) and Hallak (1990), physical facilities compose a strategic factor in the operation and functioning of an organization as they determine the excellent performance of any social organization or system including education. Physical facilities are one of the stimulating factors that play a fundamental role in improving academic achievement in the school system. These include; school buildings, accommodation, classrooms, libraries, furniture, laboratories, recreational equipments, apparatus and other instructional materials. Furthermore, their availability, relevancy and sufficiency affect academic achievement positively. On the other hand, poor school buildings and overcrowded classrooms affect academic achievement negatively. Taylor and Vlastos (2009) found the relationship between environment and design within the classroom from a theoretical perspective. They found that physical environment of the classroom acts as "Silent curriculum". It means that classroom environmental design can facilitate and improve the learning process like the overt curriculum.

Unfortunately, in Pakistan, educational institutions lack of physical facilities which results in malfunctioning of these institutions. Poor and inadequate facilities affect the overall performance of the institutions. Sufficient facilities promote academic achievement and ensure to strengthen the overall institutional performance. While unattractive and old school buildings; cracked classroom walls and floors; lack of toilets; lack of desks and benches; lack of transport facility; lack of proper security system; lack of drinking water; lack of power supply; lack of playgrounds; lack of teaching staff; lack of sufficient classrooms; overcrowded classrooms; lack of educational technology; lack of first aids facility etc negatively affect academic achievement of the institutions. Therefore, it is right to say that academic achievement has a close link with the availability of educational facilities (Hussain, et al. 2012).

There are several factors of classroom physical environment i.e. visual factor, acoustic factor, thermal factor, spatial factor and time factor. Visual factor refers to the quality of lighting in different parts of the classroom. It is determined by the level of natural and artificial light available in the classroom. It also refers to the way by which the classroom environment is arranged i.e. visually interesting, creating a favourable atmosphere and any unwanted disruptions e.g. windows overlooking playgrounds etc. Acoustic factor is an important factor as we mostly depend upon verbal communication in our classroom. Noise level mainly depends upon school design, classroom organization and teaching methodologies applied during a lesson (Basit, 2005). Poor classroom acoustics can adversely affect learning environment for many students. Constant noise exposure can damage cognitive performance and functioning (Higgins et al, 2004). Thermal factor refers to the heating and ventilation of the classroom and are generally out of the teachers' control as they are climate variables. It plays a fundamental role in making classroom atmosphere favourable and comfortable and hence affects the behaviour and performance. Spatial factor relates to the space management and has a great impact on behaviour particularly on communication. Time factor refers to the amount of time a student is participating in learning process i.e., the number of minutes the student is 
actively participating in teacher directed lessons and activities (Basit, 2005). Therefore, it is concluded that physical environment of classroom comprises of classroom size and structure, furniture, seating arrangement, instructional technologies, room heater, ceiling fans, curtains, cupboard, equipments, lighting, ventilation etc.

Proper arrangement of classroom environment plays a remarkable role in making instructional process more effective and establishes an atmosphere favourable and encouraging to learning. The quality of the physical classroom setting significantly affects academic achievement of the students. Physical facilities in classrooms ensure effective and successful teaching learning process. Without these facilities, effective and fruitful teaching learning process is not possible. Students get more information from their teachers in well facilitated classrooms and consequently they show good performance. On the other hand, if students feel uncomfortable in classroom then they will fail to get more information from their teachers. Lyons (2001) stated that poor school facilities adversely impact teachers' effectiveness and also their performance. Consequently it negatively affects student achievement. MacAulay (1990) and Walker et al (1995) found that a well-structured classroom can enhance students' academic and behavioral outcomes. Haertel, et al (1981) concluded that students' perceptions of classroom environment as an important factor that show some aspects of students' outcomes i.e., achievement, motivation and satisfaction. They further concluded that achievement in cognitive and affective learning outcomes were repeatedly associated with classrooms environment, which were perceived as having greater cohesiveness, satisfaction, goal direction, organization and less friction.

Temperature and ventilation systems inside classroom are crucial factors that affect classroom learning environment. Classrooms too cold or too hot negatively affect students' performance and concentration as they feel uncomfortable in such conditions. According to Halstead (1974), it is generally accepted that high temperature and humidity creates physiological and psychological problems which expedite fatigue, causes people to work more slowly, apply much efforts and causes to make more mistakes and errors. The classroom climate should be cautiously managed not only to provide physical comfort but also to serve as a positive factor in the learning process by stimulating attentiveness and concentration. To maintain such a climate, the atmosphere must be treated to simultaneously controlled temperature, humidity, cleanliness and circulation. Earthman (2004) established that temperature, heating and air quality are the fundamental elements for the educational attainment of students. Phillips (1992) noted that lighting is one of the most important physical characteristics of classroom. He further stated that visual environment can affect the capability of students to perceive visual stimuli and also affect their mental attitude. Consequently their academic performance is affected negatively. Culp (2006) found that success can be ensured by using visual displays in classroom. According to Winter Bottom and Wilkins (2009), there are numerous aspects of lighting to be kept in mind while taking into account this environmental characteristic of classroom. Classroom lighting consists of undetectable light, illumination at a student's desk, lighting from projection screens and windows. Improper lighting negatively affects academic achievement and promotes distress and obstruction for students in the classroom.

Proper arrangement of furniture also plays a vital and crucial role in classroom functioning. Furniture is arranged with the intention that students may feel comfortable and they may be adjusted to the primary sources or different sources of information e.g., the teacher, instructional materials, while at the same time having accessibility to other sources or the activities e.g., work areas, computers without creating disturbance in the classroom 
(Nitsaisook and Anderson, 1989). Higgins, et al (2005) noted that desk arrangement can affect students' achievement and attention. Halstead (1974) states, "A student in the classroom is properly seated if he has a clear view of the instructor, is provided with suitable writing surface and a place for book storage, is reasonably comfortable and is so situated that persons going to and from adjacent seats will not disturb him". Patton, et al (2001) found that majority (94\%) of the K-3 teachers use a semicircle or cluster to arrange the desks in their classrooms. The teachers responded that arrangement of desks in groups has several advantages i.e., encouraging cooperative learning, building a sense of class community and making the best use of the space. Proper desk arrangement provides opportunities for learners to be enthusiastically engaged in learning process and creates the opportunity to work cooperatively with their colleagues. Therefore it is imperative to make seating arrangement in such a way that it may ensure smooth functioning of instructional process.

Instructional technology plays a vital role in teaching learning process and makes it more successful, interesting and fruitful. Therefore it is imperative to arrange instructional technology in classroom to ensure effective and conducive environment for teaching learning process. Iqbal (2005) stated that the arrangement of classroom educational facilities and instructional spaces might be selected for learning rather teaching. Besides, it should ensure to facilitate teacher in making an atmosphere where quality learning may be promoted. Audio visual aids i.e., charts, graphs, maps, globes, radio, mock up, multimedia, computers, overhead projectors and internet are the part of classroom environment. However, these technologies are not being utilized in instructional programmes as were expected (Weiss, 2007) because the design of classroom physical environment does not support the integration of technology (Oliver and Lippman, 2007; Weiss, 2007; Suleman, et al., 2011). In the most of the developing countries as well as in Pakistan educational technologies are not utilized effectively during instructional process. There are some reasons which are responsible for the unsatisfactory utilization of instructional materials. Lower quality and less quantity of educational technologies provided to schools is one of the reasons. Secondly, teachers are not trained properly for the effective utilization of education technologies for instructional process (Suleman, et al. 2011). Therefore it is necessary to design classrooms in such a way that technology may be used effectively. Classrooms should be equipped with modern technologies to ensure favorable and conducive atmosphere for teaching learning process. Teacher should be given training in the utilization of technology as it is a vital component of classroom physical setting.

\section{Statement of the Problem}

The purpose of the study was to examine the effects of classroom physical environment on the academic achievement of secondary school students in Kohat Division. Therefore, the statement of the problem was designed as "Effects of Classroom Physical Environment on the Academic Achievement Scores of Secondary School Students in Kohat Division, Pakistan".

\section{Objectives of the Study}

The objectives of the study were:

1. to examine the effects of classroom physical environment on the academic achievement scores of secondary school students

2. to suggest valuable recommendations for the enhancement of students' academic achievement at secondary school level 


\section{Hypotheses of the Study}

To achieve the above mentioned objectives, the following three null hypotheses were developed:

- There is no significant difference between the performance of control and experimental groups on pre-test

- $\quad$ There is no significant difference between the performance of control and experimental groups on post-test

- There is no significant difference between the performance of control and experimental groups on retention test

\section{Method and Procedure \\ Population}

Gay (1990) stated, "A population is the group to which a researcher would like the results of a study to be generalized." All the students at secondary school level in Kohat Division, Pakistan constituted the population of the study.

\section{Delimitations of the Study}

The study was delimited to the students of Govt. High School Khurram (Karak). The study was also delimited to the students of $9^{\text {th }}$ Class. The study was further delimited to the subject of English and the following six lessons were taught during experiment:

\begin{tabular}{llll}
\hline S. No & Title of the Lessons & S. No. & Title of the Lessons \\
\hline $\mathbf{0 1}$ & I Knew a Man Who was a Giant & $\mathbf{0 4}$ & The Medina Charter \\
$\mathbf{0 2}$ & Three Days to See & $\mathbf{0 5}$ & A Fable \\
$\mathbf{0 3}$ & Quaid__A Great Leader & $\mathbf{0 6}$ & The Two Bargains \\
\hline
\end{tabular}

\section{Sample and Sampling Technique}

A sample is a subset of a population selected to participate in the study, it is a fraction of the whole, selected to participate in the research project (Brink, 1996; Polit and Hungler, 1999). The process of selecting a portion of the population to represent the entire population is known as sampling (LoBiondo-Wood and Haber, 1998; Polit and Hungler, 1999). In this research study, forty students from class $9^{\text {th }}$ of Government High School Khurram (Karak) were selected as sample using simple random sampling technique.

\section{Research Design}

As the study was experimental in nature therefore "Pre-test-Post-test Equivalent Groups Design" was used. According to this design, sample subjects are randomly allocated to exeperimental and control groups. Symbolic representation of the design is:

$\begin{array}{llllll}\mathbf{R} & \mathbf{E} & \mathbf{1} & \mathbf{O 1} & \mathbf{T} & \mathbf{O 2} \\ \mathbf{R} & \mathbf{C} & = & \mathbf{O 3} & & \mathbf{O 4}\end{array}$

Where

$$
\begin{array}{ll}
\mathrm{R}=\text { Randomly selected } & \mathrm{E}=\text { Experimental Group } \\
\mathrm{C}=\text { Control Group } & \mathrm{O}=\text { Observation or Mearsurement } \\
\mathrm{T}=\text { The experimental treatment } &
\end{array}
$$

\section{Research Instrumentation}


The study was experimental in nature therefore the pre-test and post-test technique was used as research instrument for data collection. To compare the performance of control and experimental groups, a question paper was prepared in the six lessons of English and then it was distributed among the participants of both groups before the treatment. In the same way, another paper was prepared which was administered among the students of both groups after treatment. In addition, the same question paper with slight change in sequence was used as retention test. These question papers were used as a research instruments.

\section{Data Collection}

In order to collect data, the researchers administered a pre-test, a post-test and then retention test to the both groups and thus data was collected.

\section{Data Analysis}

For the statistical anyalysis of the data, raw scores obtained from pre-test, post-test and retention test were organized and tabulated. Statistical tools, i.e., mean, standard deviation and differences of means were calculated for each group. Significance of difference between the mean scores of both the experimental and control groups on the variable of pre-test scores, post test scores and retention test scores was tested at 0.05 level of confidence by applying t-test.

\section{Selection of Teachers for Experimentation}

For the experimental treatment, two teachers having same qualifications and same teaching experience were appointed to teach the both groups. Their qualifications were M.A English and B.Ed.

\section{Arrangement of Classroom Physical Environment for Experimentation}

As the purpose of the study was to examine the effects of classroom physical environment on the academic achievement scores of secondary school students therefore it was imperative to arrange proper classroom physical settings so that the experiment may take place successfully. The researchers arranged two classrooms for the experiment with the consent of school authorities. The classroom for experimental group was equipped with various physical facilities i.e., proper desks \& chairs arrangement for students; teacher table; well painted walls; whiteboard; charts, models; overhead projector; proper lighting \& ventilation; room heaters; drinking water facility; continuous power supply; cupboard. In addition, the room was spacious also. On the other hand, the classroom for control group was only comprised of blackboard. Tots were arranged instead of desks and benches. The room was small as compared to the room of experimental group.

\section{Analysis and Data Interpretation}

The study was experimental type and sample was divided into two groups i.e. control group and experimental group on the basis of pre-test. Both the groups were taught through usual method by two English teachers. This experiment was continued for eight weeks. After the completion of the experiment, data was collected through post-test and retention test. Then it, organized, tabulated, analyzed and compared. Statistical tools i.e., mean, standard deviation and t-test were applied. The whole process is discussed as under:

Ho 1: There is no significant difference between the performance of control and experimental groups on pre-test.

Table 1: Showing the significant of difference between the mean scores of control and experimental groups on Pre-Test 


\begin{tabular}{|c|c|c|c|c|c|c|}
\hline Category & $\mathbf{N}$ & Mean & SD & $\overline{\mathbf{S E}}$ & t-value & p-value \\
\hline Experimental Group & 20 & 66.82 & 1.12 & & & \\
\hline Control Group & 20 & 66.24 & 1.06 & 0.34 & 1.68 & 0.10 \\
\hline
\end{tabular}

Table 1 indicates that the calculated value of $t$ was found to be 1.68 which is statistically non-significant ( $p>0.05$ ) because it is less than the table value of $t$ at 0.05 level. Therefore the null hypothesis that "There is no significant difference between the performance of control and experimental groups on pre-test" was accepted. Hence it was concluded that the students of both groups showed similar performance on pre-test.

$H_{0}$ 2: There is no significant difference between the performance of control and experimental groups on post-test.

Table 2: Showing the significance of difference between the mean scores of control and experimental groups on Post-Test

\begin{tabular}{lcccccc}
\hline Category & N & Mean & SD & SE & t-value & p-value \\
\hline Experimental Group & 20 & 87.02 & 1.24 & & \\
Control Group & 20 & 72.20 & 1.39 & & & \\
& & & & & & \\
\end{tabular}

\begin{tabular}{llll}
\hline *Significant & $(\mathbf{p}<0.05)$ & df $=38$ & t at 0.05 level $=2.024$
\end{tabular}

Table 2 illustrates that the calculated value of $t$ was found to be 35.58 which is statistically significant $(\mathrm{p}<0.05)$ because it is greater than the table value of $t$ at 0.05 level. So the null hypothesis that "There is no significant difference between the performance of control and experimental groups on post-test" was rejected. Hence, it was concluded that the students of experimental group showed much better performance as compared to the students of control group on post-test.

$H_{0}$ 3: There is no significant difference between the performance of control and experimental groups on retention test.

Table 3: Showing the significance of difference between the mean scores of control and experimental groups on Retention Test

\begin{tabular}{lcccccc}
\hline Category & N & Mean & SD & SE & t-value & p-value \\
\hline Experimental Group & 20 & 85.24 & 1.14 & \multirow{2}{*}{0.26} & $\mathbf{5 8 . 5 8 *}^{*}$ & 0.000 \\
Control Group & 20 & 70.22 & 1.24 & & & \\
& & & & & &
\end{tabular}

*Significant $(p=0.00<0.05) \quad$ df $=38 \quad$ t at 0.05 level $=2.024$

Table 3 depicts that the calculated value of t was found to be 58.58 which is statistically significant $(\mathrm{p}<0.05)$ because it is greater than the table value of $t$ at 0.05 level. So the null hypothesis that "There is no significant difference between the performance of control and 
experimental groups on retention test" was rejected. Hence, it was concluded that the students of experimental group performed better as compared to the students of control group on retention test.

\section{Discussion}

The purpose of the study was to examine the effects of classroom physical environment on the academic achievement scores of secondary school students in Kohat Division. The study was experimental in nature and that is why Pretest-Post-test Equivalent Group Design was used. Sample students were divided into two groups i.e. control group and experimental group on the basis of pre-test. Two different classrooms were arranged for the experiment. The classroom for experimental group was equipped with various physical facilities i.e., proper arrangement of desks \& chairs for students; teacher table; well painted walls; whiteboard; charts, models; overhead projector; proper lighting \& ventilation; room heaters; drinking water facility; continuous power supply; cupboard;. In addition, the room was spacious also. On the other hand, the classroom for control group was only comprised of blackboard. Tots were arranged instead of desks and benches. The room was small as compared to the room of experimental group. Both the groups were taught through usual method by two English teachers. This experiment was continued for eight weeks. After the completion of the experiment, the researchers administered a post-test immediately to examine the performance of the both groups. For this purpose the researchers along with English teachers made question paper in the six lessons which were taught during treatment for the both groups. After two weeks, the researchers again administered the same post-test with slight change in the sequences of the questions as a retention test. In this way data was collected, organized, tabulated, analyzed and compared.

The result of table 1 indicates that there is no significant difference between the mean scores of experimental and control group on pre-test. The calculated t-value was found to be 1.68 which is non-significant ( $p>0.05)$ at 0.05 level of confidence. Therefore it unambiguously shows that there is no significant difference between the performance of students of experimental and control group on pre-test. Thus it can be concluded that performance of students of experimental group (mean=66.82, $\mathrm{SD}=1.12$ ) and control (mean=66.24, $\mathrm{SD}=1.06$ ) group was same on pre-test. Therefore, the null hypothesis "there is no significant difference between the performance of experimental and control group on pre-test" is accepted.

The outcome of table 2 shows that there is significant difference between the mean scores of experimental and control group on post-test. The calculated t-value was found to be 35.58 which is significant $(\mathrm{p}<0.05)$ at 0.05 level of confidence. Therefore it clearly shows that there is significant difference between the performance of students of experimental and control group on post-test. Hence the result reveals that the students of experimental group (mean= 87.02, $\mathrm{SD}=1.24$ ) showed better performance as compared to the students of control group (mean=72.20, $\mathrm{SD}=1.39$ ). Therefore, the null hypothesis "there is no significant difference between the performance of experimental and control group on post-test" is rejected. Likewise MacAulay (1990) and Walker, Colvin, and Ramsey (1995) concluded that a well-structured classroom tends to improve student academic and behavioral outcomes.

Likewise the result of table 3 also depicts that there is significant difference between the mean scores of experimental and control groups on retention test. The calculated t-value was found to be 58.58 which is significant $(\mathrm{p}<0.05)$ at 0.05 level of confidence. Thus it plainly indicates that there is significant difference between the performance of students of experimental and control group on retention test. Hence the result reveals that the students of 
experimental group (mean $=85.24, \mathrm{SD}=1.14)$ showed better performance as compared to the students of control group (mean=70.22, $\mathrm{SD}=1.24$ ). Thus the null hypothesis "there is no significant difference between the performance of experimental and control group on retention test" is rejected. The results of the study also revealed that students of experimental group were found more interested, attentive and motivated during the treatment. On the other hand, students of control group were found passive, tired and frustrated.

\section{Conclusions}

In the light of statistical analysis, it was concluded that there is significant effect of classroom physical environment on the academic achievement scores of secondary school students. Well equipped classroom with physical facilities has a significant positive effect on the academic achievement scores of secondary school students. The students of experimental group obtained high scores as compared to the students of control group. Retention of the students of experimental group was found significantly better than that of the students of control group. In addition, the students of experimental group were found more motivated, interested and attentive during the treatment. In nut shell, it is concluded that if the students feel comfortable within classroom, then they will have much concentration on the lesson taught to them and that is why they will get more information from the teachers and thus they will obtain high scores.

\section{Recommendations}

Based on findings and conclusions, the researchers made the following recommendations:

1. As the study revealed that classroom physical environment plays a crucial role in strengthening students' academic achievement therefore, it is strongly recommended that classroom physical should be well structured and physical facilities should be provided to each school on priority basis.

2. As it is commonly observed that blackboards are used in public schools in this modern and advanced era, therefore, it is strongly recommended that whiteboards should be used instead of blackboards as it increases teachers' teaching efficiency.

3. All the classrooms should be decorated with maps, charts, posters and murals etc as they increase the interest, attentiveness and motivational level of the students. In addition, walls of the classrooms should be well painted.

4. Proper lighting system should be ensured so that teaching learning process may take place effectively. In addition, continuous power supply should be ensured. For this purpose, power generator should be given to each school.

5. In winter season, room heaters should be installed for warming classrooms atmosphere as unfavorable classroom temperature affects students' performance negatively.

6. Special budget should be provided to each school for purchasing classroom accessesaries. Heads of the institutions should be authorized to purchase and ensure classroom facilities.

7. Drinking water facility should be arranged inside the classroom because it will be helpful in saving students class time. In addition, dustbin should be provided to each classroom as it helps in maintaining cleanliness of the classroom.

8. Classrooms should be designed in such a way that various technologies should be used effectively. Cupboard should be provided to each classroom for keeping various accessesaries and stationery. 
9. It is commonly observed that majority of the schools lack students' furniture which badly affect students' performance. Therefore, it is strongly recommended that classroom furniture should be provided to each school on priority basis.

10. The provision of audio-visual aids and other educational technology should be ensured in classroom as it plays a crucial role in strengthening student's academic performance.

11. It is recommended that this type of research study should be conducted at elementary, higher secondary and tertiary level in other districts and provinces of the country.

\section{References}

A.I.O.U (1998). Secondary Education: Study Guide M.Ed Course Code 827. Faculty of Education, Teacher Education Department, Allama Iqbal Open University Islamabad. p. 2

Basit, A. (2005). Classroom Management Techniques at Secondary Level and Developing a Model for Urban Schools for District Peshawar. M.Phil Thesis, Faculty of Education, Allama Iqbal Open University Islamabad. pp. 16-17

Culp, B. (2005). Management of the Physical Environment in the Classroom and Gymnasium: It's not That Different. Teaching Elementary Physical Education, 17 (5), pp.13-15.

Earthman, G. I. (2004). Prioritization of 31 Criteria for School Building Adequacy. American Civil Liberties Union Foundation of Maryland. pp.11-16

$<$ http://www.aclumd.org/aTop\%20Issues/Education\%20Reform/EarthmanFinal10504.pdf >.

Fisher, E. S. (2008). The Effect of the Physical Classroom Environment on Literacy Outcomes: How $3^{\text {rd }}$ Class Teachers use the Physical Classroom to Implement a Balanced Literacy Curriculum. A Thesis presented to the Faculty of the Graduate School University of Missouri

Haertel, G. D., Walberg, H. J., \& Haertel, E. H. (1981). Socio-psychological environments and learning: A quantitative synthesis. British Educational Research Journal, 7, 27-36.

Hallack, J. (1990). Investing in the Future: Setting Educational Priorities in the Developing World. Paris 1 TEP and Pergonion Press.

Halstead, D. K. (1974). Statewide planning in higher education. Washington, D.C.: U.S. Government Printing Office. pp. 485,505-507,

Higgins, S., Hall, E., Wall, K., Woolner, P. and McCaughey, C. (2005). The Impact of School Environments: A literature review, The Centre for Learning and Teaching, School of Education, Communication and Language Science, University of Newcastle. <http://www.cfbt.com/PDF/91085.pdf>.p.18, 26

Hussain, I., Ahmad, M., Ahmad, S., Suleman, Q., Din, M. Q. and Khalid, N. (2012). A Study to Investigate the Availability of Educational Facilities at Secondary School Level in District Karak. Language in India, Strength for Today and Bright Hope for Tomorrow, India, 12 (10). pp. 234-250

Iqbal, M. (2005). A comparative study of organizational structure, leadership style and physical facilities of public and private secondary schools in Punjab and their effect on school effectiveness. Unpublished Ph.D thesis, Institute of Education \& Research, University of Punjab, Lahore.

Lang, R. H. and Hebert, J. (1995). Teaching Strategies and Methods for Students Centered Instruction, America: Whiney, H.M.

Lippman, P. C. (2010). Can the physical environment have an impact on the learning environment? CELE Exchange 2010/13 ISSN 2072-7925, (C) OECD 2010. 
Lyons, J. B. (2001). Do school facilities really impact a child's education. CEFPI Brief Issue Trak, 1-6.

MacAulay, D. J. (1990). Classroom environment: A literature review. Educational Psychology, 10(3), 239-253.

Nitsaisook, M. and Anderson, W. L. (1989). An Experimental Investigation of the Effectiveness of In-Service Teacher Education in Thailand, Department of Teacher Education, Ministry of Education, Bangkok. p.41

Oliver, C. and Lippman, P.C. (2007). Examining space and place in learning environments, paper presented at the CONNECTED International Conference on Design Education, 9-12 July, University of New South Wales, Sydney, Australia.

Oni, J.O. (1992). Resource and Resource Utilization as Correlates of School Academic Performance. Ph.D Thesis, University of Ibadan.

Partnership for 21st Century Skills. (2002). Learning for the 21st century: A report and mile guide for 21 st century skills", www.21stcenturyskills.org/images/stories/otherdocs/p21up_Report.pdf.

Patton, J. E., Snell, J., Knight, W., Willis, R., \& Gerken, K. (2001). A survey study of elementary classroom seating designs. (ERIC Document 454-194).

Phillips, R. W. (1997). Educational Facility Age and the Academic Achievement of Upper Elementary School Students. Unpublished Doctoral Dissertation. University of Georgia.

Savage, T. V. (1999). Teaching self-control through management and discipline. Boston: Allyn and Bacon.

Stewart, S. C. and Evans, W. H. (1997). Setting the stage for success: Assessing the instructional environment. Preventing School Failure, 41(2), 53-56.

Suleman, Q., Aslam, H D., Javed, T. and Hussain, I. (2011). Barriers to the Successful Integration of Educational Technology in Teaching Learning Process at Secondary School Level in Khyber Pakhtunkhwa, Pakistan. International Journal of Research in IT \& Management, 1 (8), 97-119.

Taylor, A. and Vlastos. (2009). Linking Architecture and Education: Sustainable Design for learning Environments. Albuquerque: University of New Mexico Press.

Walker, H. M., Colvin, G., \& Ramsey, E. (1995). Antisocial behavior in school: Strategies and best practices. Pacific Grove, CA: Brooks/Cole Publishing Company.

Weiss, A. (2007). Creating the Ubiquitous Classroom: Integrating Physical and Virtual Learning Spaces, in The International Journal of Learning, Vol. 14, No. 3, www.Learning-Journal.com. 